\title{
Effects of single and repeated in vitro exposure of three forms of parabens, methyl-, butyl- and propylparabens on the proliferation and estradiol secretion in MCF-7 and MCF-10A cells
}

\author{
Anna Wróbel, Ewa Ł. Gregoraszczuk \\ Department of Physiology and Toxicology of Reproduction, Jagiellonian University, Gronostajowa 9, \\ PL 30-387 Kraków, Poland \\ Correspondence: Anna Wróbel, e-mail: ania.wrobel@uj.edu.pl
}

\begin{abstract}
:
Background: Here, we analyzed the dose- $(0.2,2,20,200 \mathrm{nM}$ or $2 \mu \mathrm{M})$ and time- $(48,96,144$ and $196 \mathrm{~h})$ dependent activity of a single or repeated exposure of methyl-, butyl- and propylparaben on the proliferation of MCF-7 human breast cancer cells and MCF-10A human breast epithelial cells. Additionally, the effect on estradiol secretion, gene and protein expression of aromatase (CYP19A1) was investigated.

Methods: Cell proliferation was determined by AlamarBlue assay, and estradiol secretion by ELISA kits. Gene and protein expression of CYP19A1 was measurement using real time PCR and western blot, respectively.

Results: Stimulatory effect of a single exposure of all doses of tested parabens and time dependent effect of repeated exposure to methylparaben, propylparaben and butylparaben, the same as that of 17 $\beta$-estradiol, on proliferation of MCF-7 cells was observed. Only at low doses methyl- and butylparabens increased MCF-10A cells proliferation after single exposure, but no effect of repeated exposure was noted. Exposure at low doses of all of the parabens significantly increased $17 \beta$-estradiol (E2) secretion in MCF-7 cells but had the opposite effect on MCF-10A cells. It was correlated with gene and protein expression of CYP19A1 in MCF-7 and MCF-10 cells.

Conclusions: In summary, present study indicates a different mechanism of proliferative action of parabens in investigated cell lines. In MCF-7 breast cancer cell line it is probably due to stimulatory action on estradiol secretion and aromatase activity. In MCF-10A by an unknown mechanism, independent on stimulatory action on estradiol section, which requires further investigation.
\end{abstract}

Key words:

parabens, breast cancer cells line, proliferation, estradiol secretion

\section{Introduction}

Due to their antibacterial and preservative properties, alkyl esters of p-hydroxybenzoic acid (parabens) are commonly used in thousands of cosmetic products, including products for children [10]. The most widely used esters are methylparaben, ethylparaben, $n$-propylparaben, $n$-butylparaben and isobutylparaben.
Although, the epidemiological evidence [20] suggesting a link between the cosmetics used on the underarm and breast cancer in women is limited, information on genetic and familial breast cancers suggests that only a small minority of cases have a genetic etiology [3]. The majority of breast cancers, therefore, probably results from epigenetic changes that are induced by environmental and lifestyle factors. Data 
published by Ellsworth et al. [11] showed increased levels of genomic instability in the outer regions of the human breast in histologically normal tissue. In another publication, these authors suggested that cancer results from topically applied cosmetics [12]. The analysis of the annual quadrant incidence of breast cancer in Britain showed that $54 \%$ of breast cancers occurred in the upper outer quadrant, and the incidence cancer in these locations has been rising linearly since 1979 [5].

Moreover, parabens in their original form were detected in both the mammary gland and in breast cancer tissues [7]. For more than a century, epidemiological, clinical and experimental studies have confirmed that estrogen plays a central role in the development, progression and treatment of breast cancer [14, 19]; thus, it is important to identify the potential interactions of environmental chemicals that can enter the human breast and mimic estrogen action.

The estrogenic activity of parabens was first reported in 1998 [26]. Parabens have been shown to bind to estrogen receptors in the rodent uterus $[2,13$, $26]$ and in MCF7 human breast cancer cells $[3,6,8]$. They have been shown to upregulate the expression of the estrogen responsive reporter gene in yeast $[23,25$, $26]$ and human breast cancer cells $[3,6,8]$, and parabens can upregulate the endogenous estrogenregulated gene pS2 [3] in breast cancer cells. Parabens have also been shown to increase the uterine weight in immature rats [26] and mice [6, 8]. The fact that the estradiol-receptor blocker ICI182780 reverses the proliferative action of parabens in MCF-7 cells suggests that they bind estrogen receptors $[3,6,8]$.

Because paraben-containing cosmetics are applied every day, in this study we compared not only the effects of single and repeated in vitro exposure of three forms of the parabens, methyl-, butyl- and propylparaben, on cellular proliferation and estradiol secretion, but we also compared two different cell types: human breast cancer cells (MCF-7) and human breast epithelial cells (MCF-10A).

\section{Materials and Methods}

\section{Reagents}

Dulbecco's modified Eagle's medium without phenol red (DMEM), Dulbecco's modified Eagle's medium and Ham's F12 medium $(1: 1)$ without phenol red (DMEM/F12), charcoal-dextran, insulin, hydrocortisone and epidermal growth factor (EGF) were obtained from Sigma Chemical Co. (St. Louis, MO, USA). Fetal bovine serum (FBS, heat inactivated), horse serum (HS, heat inactivated), penicillin, streptomycin, and trypsin EDTA were obtained from PAA Laboratories GmbH (Colbe, Germany). 17 $\beta$-Estradiol (E2) was obtained from Steraloids, Inc. (Newport, RI, USA). Phosphate-buffered saline (PBS) was purchased from Biomed (Lublin, Poland). Methylparaben, $n$-propylparaben and $n$-butylparaben (Sigma Chemical Co., St. Louis, MO, USA) were dissolved in absolute ethanol. The final concentration of ethanol in the medium for each paraben was $0.2 \%$. At this concentration, ethanol has no effect on cell proliferation and apoptosis (data not shown). AlamarBlue was obtained from Invitrogen (Carlsbad, CA, USA), and the DRG Estradiol ELISA Kit was obtained from DRG Instruments GmbH (Marburg, Germany).

\section{Cell culture}

MCF-7 human breast cancer cells (ATCC, Manassas, VA, USA, passage No. 146) were routinely cultured in DMEM supplemented with $10 \%$ heat-inactivated FBS, $100 \mathrm{IU} / \mathrm{ml}$ of penicillin and $100 \mu \mathrm{g}$ of streptomycin. Twenty-four hours before the experiments, the medium was removed and replaced with DMEM without phenol red supplemented with 5\% dextrancoated, charcoal-treated FBS (5\% DC-FBS) to exclude estrogenic effects caused by the medium. Then, the cells were plated in the same medium and allowed to attach overnight.

MCF-10A human breast epithelial cells (ATCC, Manassas, VA, USA, passage No. 105) were routinely cultured in DMEM/F12 supplemented with $20 \mathrm{ng} / \mathrm{ml}$ epidermal growth factor, $0.01 \mathrm{mg} / \mathrm{ml}$ insulin, $500 \mathrm{ng} /$ $\mathrm{ml}$ hydrocortisone, 5\% heat-inactivated HS, $100 \mathrm{IU} /$ $\mathrm{ml}$ of penicillin and $100 \mu \mathrm{g}$ of streptomycin. Twentyfour hours before the experiments, the medium was removed and replaced with DMEM/F12 without phenol red supplemented with $0.01 \mathrm{mg} / \mathrm{ml}$ insulin, $500 \mathrm{ng} / \mathrm{ml}$ hydrocortisone, and 5\% dextran-coated charcoal-treated HS ( $5 \%$ DC-HS). Then, the cells were plated in the same medium and allowed to attach overnight.

The cells were cultured in a humidified atmosphere at $5 \% \mathrm{CO}_{2}$ at $37^{\circ} \mathrm{C}$. 


\section{Real-time PCR analysis}

The MCF-7 cells were seeded in 96-well plates at a density of $15 \times 10^{3}$ cells per well, whereas MCF$10 \mathrm{~A}$ cells were seeded at a density of $12 \times 10^{3}$ cells per well. Methylparaben, $n$-propylparaben and $n$ butylparaben were added at dose of $20 \mathrm{nM}$ and $17 \beta$ estradiol was added at dose of $100 \mathrm{nM}$ for $24 \mathrm{~h}$. Total RNA isolation and cDNA synthesis was performed using the TaqMan Gene Expression Cell-to-CT Kit (Applied Biosystems, Carlsbad, CA, USA) according to the manufacturer's protocol. The lysis solution contained DNAse I to remove genomic DNA during the cell lysis. Resulting pre-amplified cDNA preparations were analyzed by real-time PCR in a StepOnePlus Real-time PCR System (Applied Biosystems, Foster City, CA, USA) using the TaqMan Gene Expression Assay in combination with TaqMan Gene Expression Master Mix containing ROX (Applied Biosystems, Foster City, CA, USA) according to the manufacturer's instructions. The following PCR conditions were used: incubation for $2 \mathrm{~min}$ at $50^{\circ} \mathrm{C}$, followed by incubation for $10 \mathrm{~min}$ at $95^{\circ} \mathrm{C}, 40$ cycles (denaturation step: $15 \mathrm{~s}$ at $95^{\circ} \mathrm{C}$; annealing/elongation step: $60 \mathrm{~s}$ at $60^{\circ} \mathrm{C}$ ). Duplicate samples without cDNA for each gene showed no DNA contamination.

The relative expression of CYP19A1 (Hs00903413_m1) was normalized to GAPDH (Hs99999905_m1) $(\Delta \mathrm{Ct})$ to compensate for differences in the amount of cDNA (assay identification number) and converted to a relative expression quantity using the $2^{-\Delta \Lambda C}$ T method [18]. TaqMan Gene Expression Assay (Hs00903413_m1) coding homo sapiens cytochrome P450, family 19, subfamily A, polypeptide 1 (CYP19A1), transcript variant 1, mRNA (NCBI Reference Sequence: NM_000103.3) and transcript variant 2, mRNA (NM_031226.2).

\section{Western blot}

The MCF-7 cells were seeded in 48 -well plates at a density of $15 \times 10^{4}$ cells per well, whereas MCF$10 \mathrm{~A}$ cells were seeded at a density of $2 \times 10^{5}$ cells per well. Methylparaben, $n$-propylparaben and $n$-butylparaben were added at a dose of $20 \mathrm{nM}$ and $17 \beta$-estradiol was added at a dose of $100 \mathrm{nM}$. After $24 \mathrm{~h}$ of incubation, cells were transferred into ice-cold lysis buffer (50 mM Tris- $\mathrm{HCl} \mathrm{pH} 7.5 ; 100 \mathrm{mM} \mathrm{NaCl} ; 0.5 \%$ Na-deoxycholate; $0.5 \%$ Nonidet NP- $40 ; 0.5 \%$ sodium dodecyl sulfate and protease inhibitor EDTA-free). Total cell lysates were prepared and stored at $-70^{\circ} \mathrm{C}$.

Protein concentrations were determined using the Bradford reagent (Bio-Rad Protein, Bio-Rad Laboratories, Inc., CA, USA). Equal amounts of protein $(20 \mu \mathrm{g})$ were separated by $10 \%$ SDS-polyacrylamide gel electrophoresis in a Bio-Rad Mini-Protean II Electrophoresis Cell. After electrophoretic separation, the proteins were electrotransferred to PVDF membranes and washed. The blots were blocked in 5\% dry milk with $0.1 \%$ Tween-20 in $0.02 \mathrm{M}$ TBS buffer for $1 \mathrm{~h}$. Blots were incubated overnight with antibodies specific to CYP19 (sc-14244, from Santa Cruz Biotechnology) and $\beta$-actin (A5316, from Sigma Chemical Co., MO, USA). After incubation with the primary antibody, the membranes were washed three times and incubated for $1 \mathrm{~h}$ with a horseradish peroxidaseconjugated secondary antibody: P0447 (DakoCytomation, Denmark) for $\beta$-actin and sc-2020 (Santa Cruz Biotechnology) for CYP19. Bands were detected by chemiluminescence (ECL) using Western Blotting Luminol Reagent (sc-2048, Santa Cruz Biotechnology) and visualized using a ChemidocTM XRS+ System (BioRad, Laboratories). Data visualized by chemiluminescence were quantified using a densitometer and quantitated with Image LabTM 2.0 Software (Bio-Rad, Laboratories).

\section{Estradiol secretion}

As in proliferation assay, the MCF-7 cells were seeded in 96-well culture plates at a density of $9 \times 10^{3}$ cells per well, while the MCF-10A cells were seeded at a density of $12 \times 10^{3}$ cells per well. The cells were cultured in the appropriate medium (see cell culture) at five different doses $(0.2,2,20,200 \mathrm{nM}$, or $2 \mu \mathrm{M})$ of methylparaben, $n$-propylparaben and $n$-butylparaben for $72 \mathrm{~h}$. At the end of the culture, the media were collected and stored at $-20^{\circ} \mathrm{C}$.

The estradiol concentrations were determined using the enzyme immunoassay DRG Estradiol ELISA Kit (DRG Instruments GmbH, Marburg, Germany) according to the manufacturer's instructions. The sensitivity of the assay was $9.714 \mathrm{pg} / \mathrm{ml}$, the intraassay variation was $4.13-6.81 \%$, the inter-assay variation was $7.25-9.39 \%$, and the linear range was 0-2000 pg/ml. The absorbance values were measured at a wavelength of $450 \mathrm{~nm}$ using an ELISA reader (ELx808 BIO-TEK Instruments, USA). 


\section{Cell proliferation}

The AlamarBlue colorimetric assay was used to evaluate cell proliferation. Metabolically active cells convert resazurin to the fluorescent metabolite resorufin, and the fluorescence reading of the sample is proportional to the number of living cells in the sample.

MCF-7 cells were seeded in 96-well culture plates at a density of $9 \times 10^{3}$ cells per well, whereas MCF-10A cells were seeded at a density of $12 \times 10^{3}$ cells per well. Methylparaben, $n$-propylparaben and $n$-butylparaben were added at doses of $0.2,2,20,200 \mathrm{nM}$ or $2 \mu \mathrm{M}$ and $17 \beta$-estradiol was added at a dose of $100 \mathrm{nM}$. To evaluate the activity of a single exposure, the parabens were added once at the beginning of the culture.

After 3 days, the culture medium was replaced with fresh media without compounds and incubated for 3 more days. To evaluate the action of repeated exposures, the parabens were added at the beginning and then every $48 \mathrm{~h}$ for 6 days. Thus, the compounds were added three times during the experiment.

After $48,96,144$ and $194 \mathrm{~h}$ of culture in the repeated exposure experiments and at the end of the culture in the single exposure experiments, AlamarBlue stock solution was aseptically added to the wells in amounts equal to $10 \%$ of the incubation volume and was incubated for $5 \mathrm{~h}$
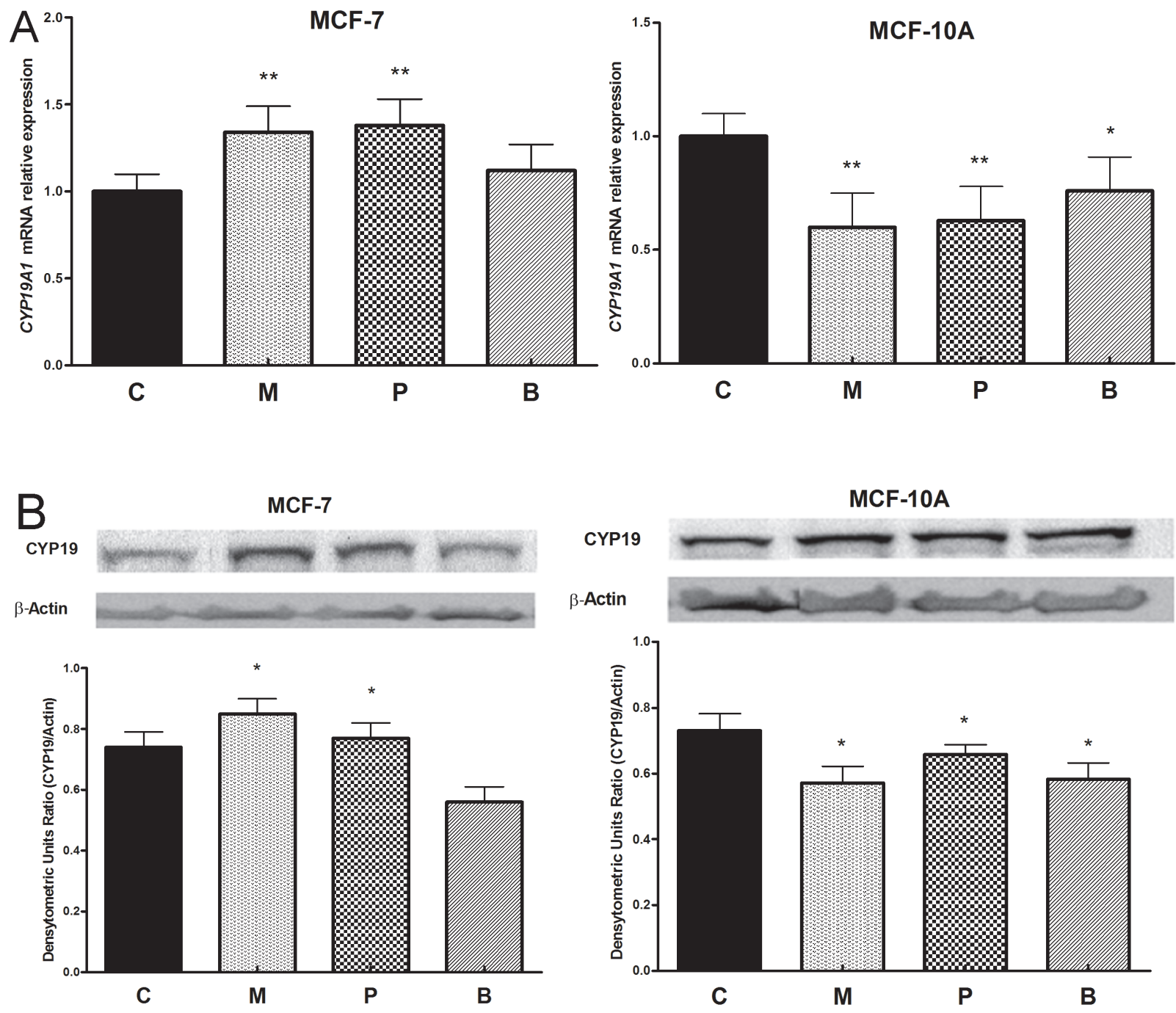

Fig. 1. The effect of methyl-, propyl- and butylparabens on (A) CYP19A1 mRNA expression after $24 \mathrm{~h}$ exposure. CYP19A1 mRNA determined by real time PCR and expressed as relative values to basal conditions and (B) CYP19A1 protein expression determined by western blot. CYP19A1 densitometry results were normalized to $\beta$-actin loading controls to obtain (CYP19A1/ $\beta$-actin ratio). All data were derived from a minimum of three independent experiments using different cell preparations. All means marked with * $(p<0.05)$ and ${ }^{* *}(p<0.01)$ are significantly different from the control 

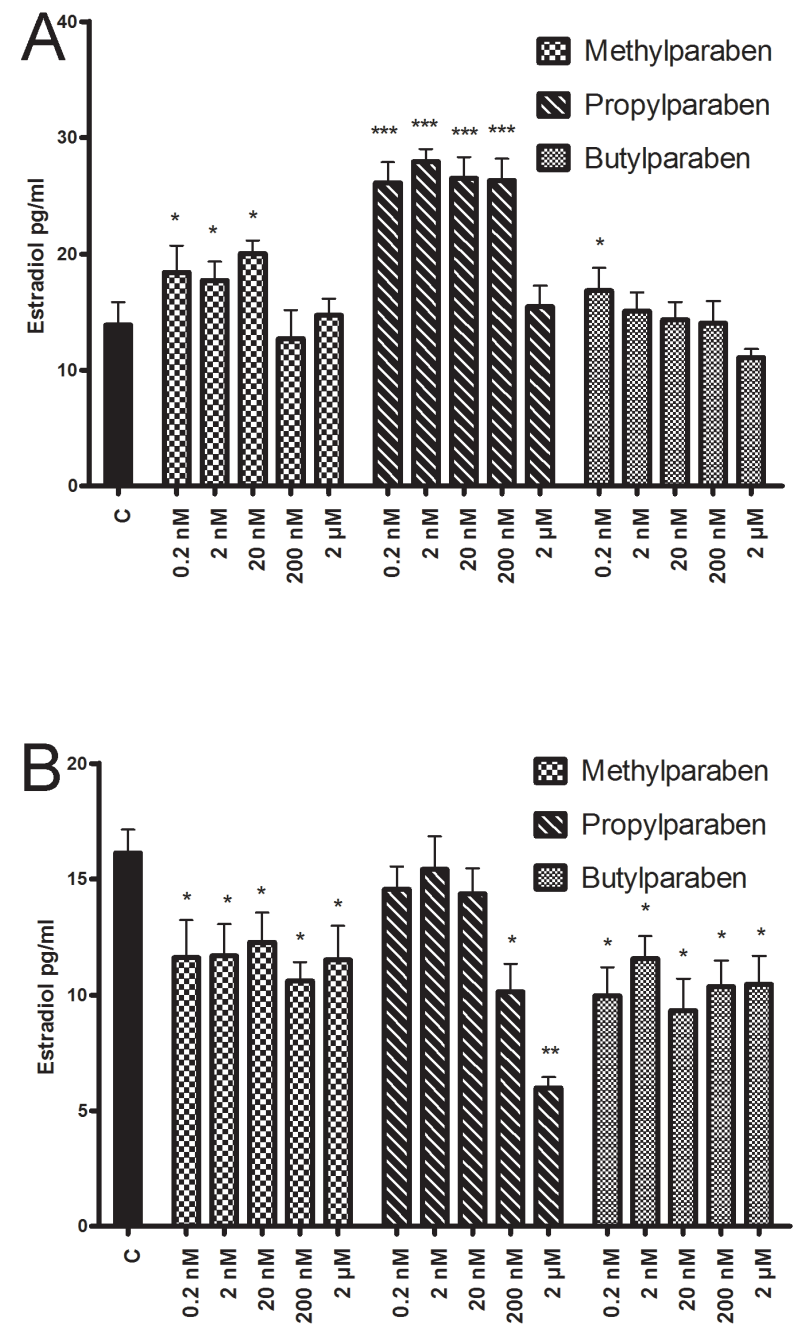

Fig. 2. Estradiol secretion by (A) MCF-7 and (B) MCF-10A breast epithelial cells after $72 \mathrm{~h}$ of exposure to methyl-, butyl- and propylparabens. Each point represents the mean \pm SEM of results from three independent experiments; each experiment consisted of six replicates per treatment group. All of the means that are marked with * $(p<0.05)$; ${ }^{* *}(p<0.01)$ and ${ }^{* * *}(p<0.001)$ are significantly different from the control

with the cells. The resazurin reduction was measured at a $540 \mathrm{~nm}$ excitation wavelength and $590 \mathrm{~nm}$ emission wavelength using a FLUORO-microplate reader (BIO-TECH Instruments, USA).

\section{Statistical analysis}

Each experiment was repeated three times $(n=3)$, and every repetition of each experiment was run in quadruplicate. The statistical analyses were performed using GraphPad Prism 5. The data were analyzed by one-way analysis of variance (ANOVA) followed by
Tukey’s Honestly Significant Differences (HSD) multiple range test.

\section{Results}

\section{Action of methyl-, butyl- and propylparabens on CYP19A1 gene (Fig. 1A) and protein expression (Fig. 1B) in MCF-7and MCF-10A cells}

CYP19A1 mRNA expression was detected in both MCF-7 breast cancer cells and MCF-10A human breast epithelial cells. In MCF-7 cells, CYP19A1 mRNA expression significantly increased after treatment with methyl- and propylparabens $(\mathrm{p}<0.01)$ while in MCF-10A cells, all tested parabens statistically significantly decreased CYP19A1 mRNA expression $(\mathrm{p}<0.5)$.

CYP19A1 protein expression was detected in both MCF-7 breast cancer cells and MCF-10A human breast epithelial cells. In MCF-7 breast cancer cells CYP19A1 protein expression significantly increased after exposure to methyl- and propylparabens $(p<0.5)$ while in MCF-10A cells all tested parabens decreased CYP19A1 protein expression $(\mathrm{p}<0.5)$.

The effect of methyl-, butyl- and propylparabens (Fig. 2A) on estradiol secretion in MCF-7 breast cancer cells

A seventy-two hour exposure to methylparaben at doses of $0.2,2$ and $20 \mathrm{nM}$ caused a statistically significant increase in estradiol secretion $(p>0.05)$. Butylparaben stimulated estradiol secretion $(p>0.05)$ only at the lowest dose $(0.2 \mathrm{nM})$. A 2-fold stimulatory action on estradiol secretion was observed in the presence of propylparaben at doses of $0.2,2,20$ and $200 \mathrm{nM}(\mathrm{p}>0.001)$.

The effect of methyl-, butyl- and propylparabens (Fig. 2B) on estradiol secretion in MCF-10A breast epithelial cells

At all tested doses, methylparaben and butylparaben decreased E2 secretion (30\% below the control, $p$ > $0.05)$. Propylparaben caused a statistically significant decrease in estradiol secretion in MCF-10A cells only at the two highest doses $(200 \mathrm{nM}$ and $2 \mu \mathrm{M})(\mathrm{p}<0.05$ and $\mathrm{p}>0.01$, respectively). 
The effect of a single exposure of parabens (methyl-, butyl- and propylparabens) and $17 \beta$-estradiol on the proliferation of MCF-7 (Fig. 3A) and MCF-10A (Fig. 3B) cells

$17 \beta$-Estradiol alone at a concentration of $100 \mathrm{nM}$ caused a statistically significant increase in the proliferation of MCF-7 cells ( $25 \%$ above the control, $\mathrm{p}<$ 0.05 ) but not in the proliferation of MCF-10A cells.

Exposure of MCF-7 (Fig. 3A) cells to methyl-, butyl- and propylparaben at doses of $0.2,2,20$ and $200 \mathrm{nM}$ caused a statistically significant increase in the proliferation of MCF-7 cells compared to the con-
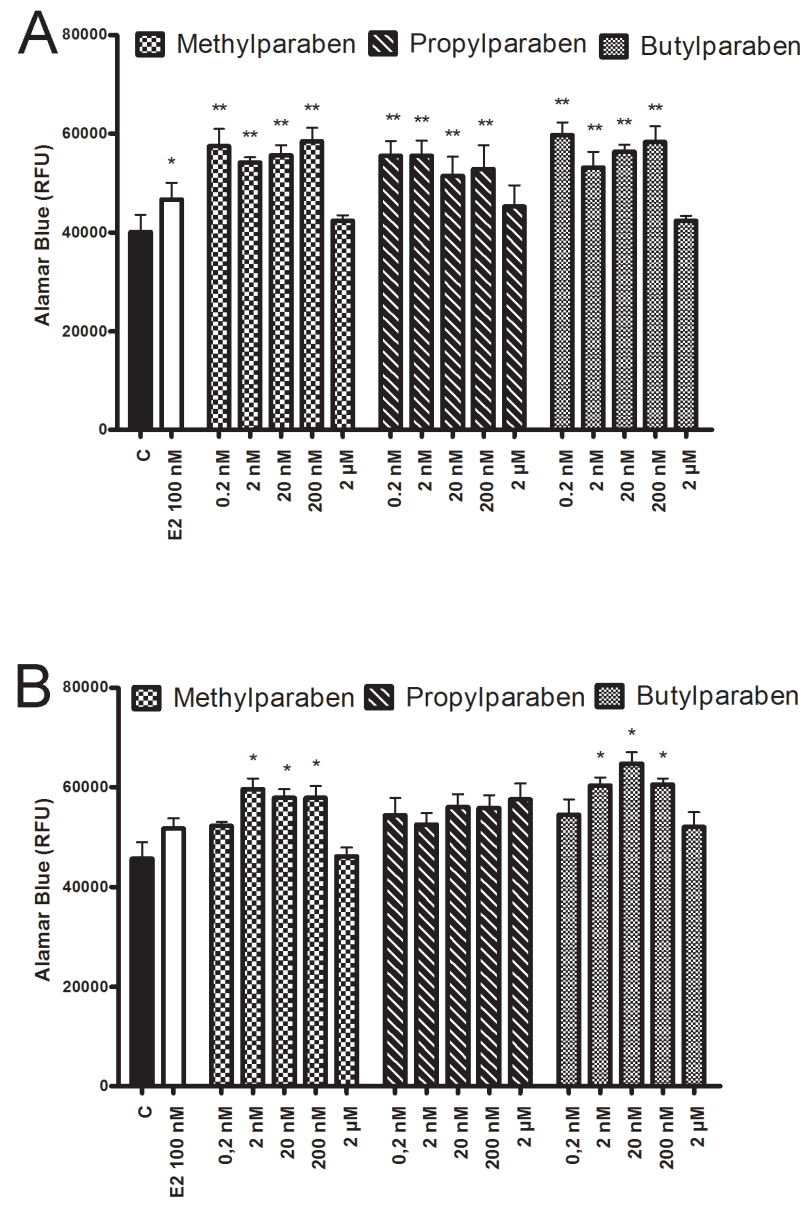

Fig. 3. The effect of a single exposure to different concentrations of methyl-, butyl- and propylparabens on the proliferation of (A) MCF-7 human breast cancer cells and (B) MCF-10A human breast epithelia cells. To evaluate the activity of a single exposure, the parabens were added once at the beginning of the culture. After 3 days, the culture medium was replaced with fresh media without compounds and incubated for 3 more days. Each point represents the mean \pm SEM from three independent experiments; each experiment consisted of six replicates per treatment group. All of the means that are marked with * $(p<0.05)$ or ** $(p<0.01)$ are significantly different from the control trol $(40 \%$ above control, $\mathrm{p}<0.01)$ and to $17 \beta$-estradiol $(15 \%$ above estradiol, $\mathrm{p}<0.05)$.

Exposure of MCF-10A (Fig. 3B) cells to methylparaben and butylparaben at doses of 2, 20 and $200 \mathrm{nM}$ caused a statistically significant increase in the basal proliferation of MCF-10A cells (30\% above control, $\mathrm{p}<0.05)$. Propylparaben had no effect on MCF-10A cell proliferation.

\section{The effect of repeated exposure of parabens (methyl-, propyl- and butylparabens) and $17 \beta$-estradiol on the proliferation of MCF-7} (Fig. 4A-C) and MCF-10A (Fig. 4D-F) cells

$17 \beta$-Estradiol alone at a concentration of $100 \mathrm{nM}$ caused a statistically significant increase in the proliferation of MCF-7 cells (30\% above the control after $96 \mathrm{~h}, \mathrm{p}<0.05 ; 25 \%$ above the control after $144 \mathrm{~h}$ and $194 \mathrm{~h}, \mathrm{p}<0.05)$.

Methylparaben (Fig. 4A) used at doses of 0.2 and $2 \mathrm{nM}$, which were the same levels as 17ß-estradiol, caused a statistically significant increase in the proliferation of MCF- 7 cells $(25 \%$ above the control, $p<0.05$ after $144 \mathrm{~h}$ ), and in all tested doses after $194 \mathrm{~h}$ of culture.

After only $96 \mathrm{~h}$ of culture at all of the tested doses, butylparaben (Fig. 4B) caused a statistically significant increase in the proliferation of MCF-7 cells (from 35 to $45 \%$ above the control, $\mathrm{p}<0.01$ ). Butylparaben doses of $0.2,2,20$ and $200 \mathrm{nM}$ had a stronger effect than $17 \beta$-estradiol (15\% to $25 \%$ above estradiol, $\mathrm{p}<0.05)$.

After 96, 144 and $194 \mathrm{~h}$ of culture at all of the tested doses, propylparaben (Fig. 4C) caused a statistically significant increase in cell proliferation in the same manner as $17 \beta$-estradiol (from 25 to $30 \%$ above the control, $\mathrm{p}<0.05$ ).

Any statistically significantly effect on cell proliferation was observed after exposure of MCF-10A to both $17 \beta$-estradiol and parabens (Fig. 4D-F).

\section{Discussion}

The presented results showed CYP19A1 gene, protein expression and estradiol secretion in both cell lines. Additionally, presented results showed higher basal estradiol secreted by MCF-10A than MCF-7 cells. The presence of CYP19A1 gene expression in MCF-7 

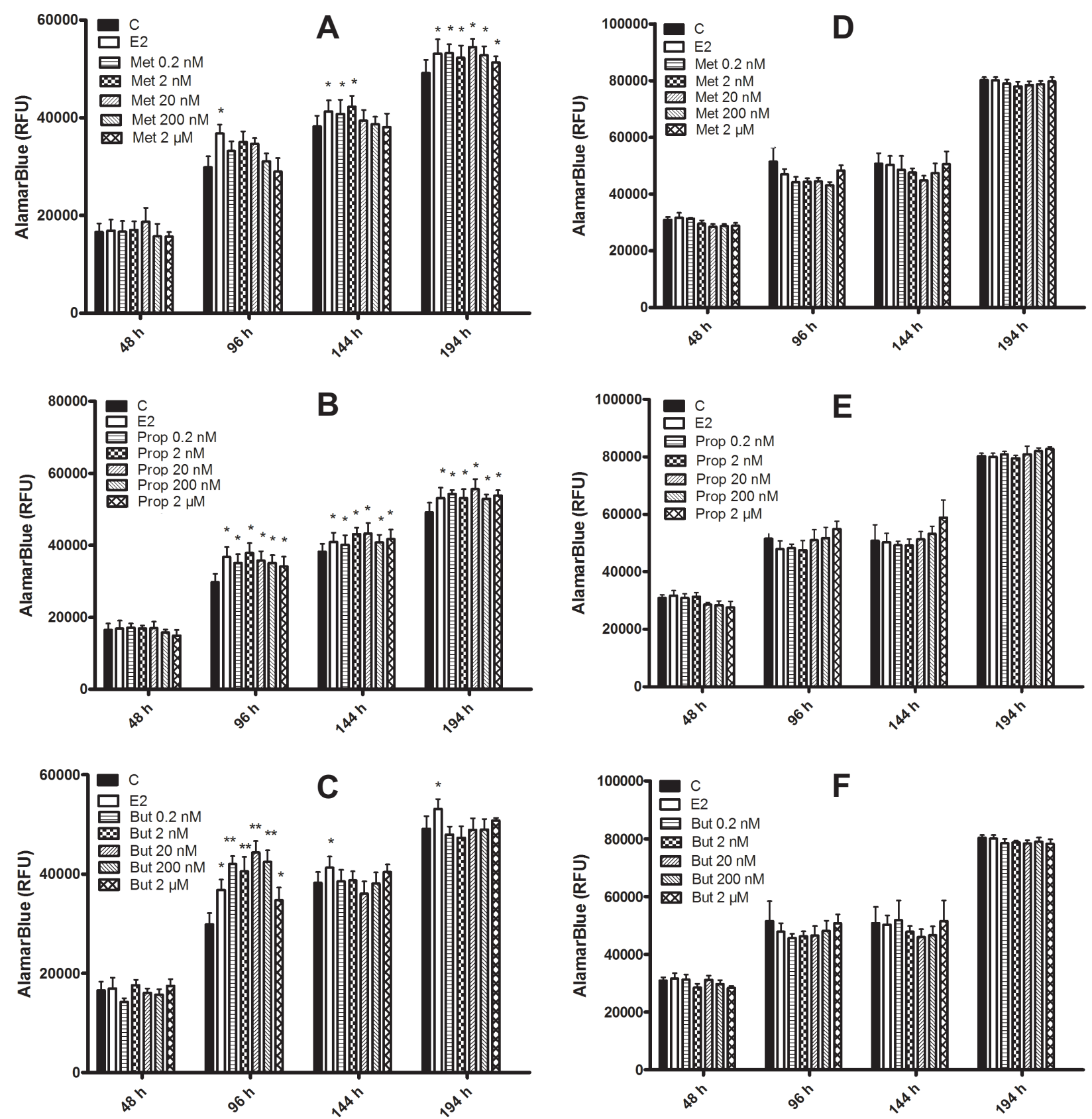

Fig. 4. The effect of repeated exposures to different concentrations of methylparaben (A), propylparaben (B) and butylparaben (C) on the proliferation of MCF-7 breast cancer cells and effect of repeated exposures of methylparaben (D), propylparaben (E) and butylparaben (F) on the proliferation of MCF-10A breast epithelial cells after 48,96, 144 and $194 \mathrm{~h}$ of culture. To evaluate the action of repeated exposures, the medium was changed before the repeated treatment with parabens. The parabens were added at the beginning and then every $48 \mathrm{~h}$ for $6 \mathrm{days}$. Thus, the compounds were added three times during the experiment. Each point represents the mean \pm SEM from three independent experiments; each experiment consisted of six replicates per treatment group. All of the means that are marked with * $(p<0.05)$ and ** $(p<0.01)$ are significantly different from the control

described by Hevir et al. [15] confirms our results. However, according to Hevir et al. [15] MCF-10A did not expressed CYP19A1 gene expression. This discrepancy requires further investigation, taking into consideration identical culture conditions and method for the determination of gene expression. It should be noted that Hevir et al. [15] and our presented data are the only showing CYP19A1 gene expression in 
MCF-10A cells. However, results of our study were supported by demonstrating not only CYP19A1 gene but also protein expression and estradiol secretion.

The second interesting finding presented here is stimulatory effect of methyl- and propylparaben on CYP19A1 gene, protein expression and estradiol secretion in MCF-7 cell line. Our results indicate that estrogenic action of parabens is not only a consequence of the estradiol receptor binding capabilities $[13,15]$ and activities as exogenous estrogens, but is also the result of an ability to stimulate the secretion of estradiol. The increase in E2 secretion in MCF-7 cells is mostly due to the stimulatory effect of parabens on CYP19A1 gene, protein expression. The opposite effect was noted in MCF-10 cells line. Inhibitory effect of all tested parabens on CYP19A1 gene, protein expression and estradiol secretion was described. This results are in agreement with data of von Meeuwen et al. [29], who showed inhibition of aromatase by methyl-, ethyl-, propyl- and isopropylparabens.

In the next part of this study, we looked for the action of parabens on cells proliferation. These results show a stimulatory effect of a single in vitro exposure to all of the tested parabens at all doses used on MCF-7 human breast cancer cells. A stimulatory activity on the proliferation of MCF-10A human breast epithelial cells was observed only at low doses of methyl- and butylparabens.

There are data concerning the activity of parabens on breast cancer cell lines. Boyford et al. [3] showed a stimulatory effect of parabens on the proliferation of MCF-7 cells at concentrations of 1 and $10 \mathrm{mM}$, whereas there was an absence of any effect of the test compounds at lower concentrations $(0.1 \mathrm{nM}$ to $0.1 \mathrm{mM})$. Similar findings were reported by both Okubo et al. [23] after 6 days of exposure and also by Pugazhendhi et al. [25] after 7 days of exposure. Increased MCF-7 cells proliferation after treatment with parabens have been also described by Vanparys et al. [27] and van Meeuwen et al. [29].

Darbre et al. [5, 8] using the estrogen-dependent breast cancer cell lines MCF-7, ZR-75-1 and the estrogen receptor negative MDA-MB-231 human breast cancer cell line, showed that isobutylparaben and benzylparaben used at doses from 1 to $100 \mathrm{mM}$ increased the proliferation of MCF-7 and ZR-75-1 cells; however, both of the test compounds had no proliferative effects on the MDA-MB-231 estrogen-receptor-negative cell line. In the data presented here, using very low doses of parabens (nM and $\mu \mathrm{M}$ ), we noted an increase in cell proliferation in both cell lines.
Additionally, most of these authors count cells in a Cultured Counter, whereas in our experiment, we used methods that measure the cellular viability functions as an indicator of cellular health to quantitatively measure the proliferations. From our experience (data not published), parabens used in doses higher than $20 \mu \mathrm{M}$ have a cytotoxic effect.

To our knowledge, these data are the first to demonstrate the effect of parabens on the proliferation of MCF-10A cells. MCF-10A is a spontaneously immortalized but nontransformed human mammary epithelial cell line and is often considered to represent normal human mammary epithelial cells. However, MCF-10A cells acquire the ability to transform into cancer cells under the action of carcinogenic [1], mutagenic [31] and dioxin-like compounds such as TCDD, PCDF and PCB [28]. This ability, among others, is manifested by an increase in cell proliferation $[1,28,31]$. The results presented here suggest that parabens can also initiate the process of MCF-10A transformation. However, this hypothesis still requires a thorough examination. The fact that all of the above mentioned authors observed a stimulatory activity of parabens only at high doses may be due to different culture conditions and a preincubation in medium supplemented with insulin and $17 \beta$-estradiol. It was observed that estradiol protects the human breast cancer cell line MCF-7 from apoptosis induced by UV radiation [24]. Sang-Han Lee et al. [17] showed that E2 may partly provide a survival advantage through the regulation of cellular oxidative homeostasis in MCF-7 breast cancer cells.

Our studies show for the first time that at low doses parabens have the potential to stimulate the proliferation of MCF-7 and MCF-10A cells. This response is widely considered to be a curve-linear or hormesis response and is characterized by a modest stimulatory effect at low doses and an inhibition or absence of a response at high concentrations [4]. In toxicology, an expected dose-response relationship is frequently used as a basis for risk assessment. The threshold model, or the linear non-threshold (LNT) model, is commonly used. Early investigations showed that estrogens are mitogens and can stimulate cell proliferation at very low concentrations [30]. Many xenoestrogens have the potential to cause responses at low doses and can cause inhibition or toxicity at large doses. For example, this was demonstrated for exposure to low doses of bisphenol A, octylphenol and the estrogenic drug diethylstilbestrol $[9,16,21]$. There- 
fore, man made xenoestrogens should receive special treatment during risk assessment because even very low concentrations may cause responses deviating from the norm.

Surprisingly, methylparaben, butylparaben and propylparaben had no effect on the proliferation of MCF-10A cells after repeated exposure; the lack of an effect was independent of the concentration used. The stimulatory effect of methylparaben after $144 \mathrm{~h}$ of culture and propylparaben after $96 \mathrm{~h}$ of culture was the same as that of $17 \beta$-estradiol, whereas after only $96 \mathrm{~h}$ of culture, butylparaben increased the proliferation of MCF-7 cells to higher levels than did estradiol. To our knowledge, there are no data that test the influence of repeated exposure of these compounds. However, it is important to consider that parabens, which are present in most cosmetics, are applied daily - not just once. Parabens have been shown to bind to estrogen receptors $(\alpha$ and $\beta$ ) from different sources, including the rodent uterus $[2,13,26]$ and MCF7 human breast cancer cells $[3,6,8]$. Using the antiestrogen ICI 182 780, the estrogen-receptor mediated stimulatory effects of parabens on the proliferation of MCF-7 cells has been shown $[3,6,8]$. There are data showing upregulation of the expression of the estrogen responsive reporter gene in yeast $[23,25,26] \mathrm{hu}-$ man breast cancer cells $[3,6,8]$ and the estrogenregulated gene pS2 [3] in breast cancer cells under the influence of parabens. Similar to other environmental estrogens, butylparaben has also been shown to alter reproductive function in male rats, including a reduction in sperm counts [22]. An increase in uterine weight in immature rats [26] and immature mice [6, 8] confirm the estrogenic activity of parabens. Our data show that butylparaben has the strongest estrogenic activity - as strong as estradiol. There are studies indicating that the estrogenic activity of parabens increases with an increasing length of the linear alkyl chain $[3,26]$ and with branching in the alkyl chain. This would predict that butylparaben would have the highest estrogenic potential. Indeed, the data shown here support this hypothesis.

In summary, present study indicates a different mechanism of proliferative action of parabens in investigated cell lines. In MCF-7 breast cancer cell lines this is probably due to stimulatory action on estradiol secretion and aromatase activity. In MCF-10A by an unknown mechanism, independent on stimulatory action on estradiol section, which requires further investigation.

\section{Acknowledgments:}

This work was supported by the National Sciences Center from 2011 to 2014 as a project DEC-2011/01/N/NZ7/00015 and partly by DS/MND/WBiNoZ/IZ/29/2011. This paper includes some of the data presented in Anna Wróbel's PhD dissertation.

\section{References:}

1. Benbrahim-Tallaa L, Tokar EJ, Diwan BA, Dill AL, Coppin JF, Waalkes MP: Cadmium malignantly transforms normal human breast epithelial cells into a basallike phenotype. Environ Health Perspect, 2009, 117, 1847-1852.

2. Blair RM, Fang H, Branham WS, Hass BS, Dial SL, Moland CL, Tong $\mathrm{W}$ et al.: The estrogen receptor relative binding affinities of 188 natural and xenochemicals: structural diversity of ligands. Toxicol Sci, 2000, 54, 138-153.

3. Byford JR, Shaw LE, Drew MG, Pope GS, Sauer MJ, Darbre PD: Oestrogenic activity of parabens in MCF7 human breast cancer cells. J Steroid Biochem Mol Biol, 2002, 80, 49-60.

4. Calabrese EJ, Baldwin LA: The hormetic dose-response model is more common than the threshold model in toxicology. Toxicol Sci, 2003, 71, 246-250.

5. Darbre PD: Environmental oestrogens, cosmetics and breast cancer. Best Pract Res Clin Endocrinol Metab, 2006, 20, 121-143.

6. Darbre PD: Underarm cosmetics and breast cancer. J Appl Toxicol, 2003, 23, 89-95.

7. Darbre PD, Aljarrah A, Miller WR, Coldham NG, Sauer MJ, Pope GS: Concentrations of parabens in human breast tumors. J. Appl Toxicol, 2004, 24, 5-13.

8. Darbre PD, Byford JR, Shaw LE, Horton RA, Pope GS, Sauer MJ: Oestrogenic activity of isobutylparaben in vitro and in vivo. J Appl Toxicol, 2002, 22, 219-226.

9. Duft M, Schulte-Oehlmann U, Weltje L, Tillmann M, Oehlmann J: Stimulated embryo production as a parameter of estrogenic exposure via sediments in the freshwater mudsnail Potamopyrgus antipodarum. Aquat Toxicol, 2003, 64, 437-449.

10. Elder RL: The cosmetic ingredient review - a safety evaluation program. J Am Acad Dermatol, 1984, 11, 1168-1174.

11. Ellsworth DL, Ellsworth RE, Liebman MN, Hooke JA, Shriver CD: Genomic instability in histologically normal breast tissues: implications for carcinogenesis. Lancet Oncol, 2004, 5, 753-758.

12. Ellsworth DL, Ellsworth RE, Love B, Deyarmin B, Lubert SM, Mittal V, Hooke JA, Shriver CD: Outer breast quadrants demonstrate increased levels of genomic instability. Ann Surg Oncol, 2004, 11, 861-868.

13. Fang H, Tong W, Shi LM, Blair R, Perkins R, Branham W, Hass BS et al.: Structure-activity relationships for a large diverse set of natural, synthetic, and environmental estrogens. Chem Res Toxicol, 2001, 14, 280-294.

14. Hawkins RA, Tesdale AL, Killen ME, Jack WJ, Chetty U, Dixon JM, Hulme MJ et al.: Prospective evaluation of 
prognostic factors in operable breast cancer. Br J Cancer, 1996, 74, 1469-1478.

15. Hevir N, Trošt N, Debeljak N, Lanišnik Rižner T: Expression of estrogen and progesterone receptors and estrogen metabolizing enzymes in different breast cancer cell lines. Chem Biol Interact, 2011, 191, 206-216.

16. Jobling S, Casey D, Rodgers-Gray T, Oehlmann J, Schulte-Oehlmann U, Pawlowski S, Braunbeck T et al.: Comparative responses of mollusks and fish to environmental estrogens and an estrogenic effluent. Aquat Toxicol, 2004, 66, 207-222.

17. Lee SH, Kim HJ, Kang HJ, Lee YJ, Nam HS, Bae I: Reactive oxygen species generated by $17 \beta$-estradiol play a role in the up-regulation of GPX4 protein in MCF-7 breast cancer cells. J Breast Cancer, 2009, 12, 134-141.

18. Livak KJ, Schmittgen TD: Analysis of relative gene expression data using real-time quantitative PCR and the $2^{-\Delta \Delta C}$ T) Method. Methods, 2001, 25, 402-408.

19. Lonning PE: Endocrinology and treatment of breast cancer. Clin Endocrinol Metab, 2004, 18, 1-130.

20. McGrath KG: An earlier age of breast cancer diagnosis related to more frequent use of antiperspirants/deodorants and underarm shaving. Eur J Cancer Prev, 2003, 12, 479-485.

21. Oehlmann J, Schulte-Oehlmann U, Tillmann M, Markert B: Effects of endocrine disruptors on prosobranch snails (Mollusca: Gastropoda) in the laboratory. Part I: Bisphenol A and octylphenol as xeno-estrogens. Ecotoxicology, 2000, 9, 383-397.

22. Oishi S: Effects of butylparaben on the male reproductive system in rats. Toxicol Ind Health, 2001, 17, 31-39.

23. Okubo T, Yokoyama Y, Kano K, Kano I: ER-dependent estrogenic activity of parabens assessed by proliferation of human breast cancer MCF-7 cells and expression of ER $\alpha$ and PR. Food Chem Toxicol, 2001, 39, 1225-1232.

24. Pedram A, Razandi M, Wallace DC, Levin ER: Functional estrogen receptors in mitochondria of breast cancer cells. Mol Biol Cell, 2006, 17, 2125-2137.
25. Pugazhendhi D, Pope GS, Darber PD: Oestrogenic activity of $p$-hydroxybenzoic acid (common metabolite of paraben esters) and methylparaben in human breast cancer cell lines. J Appl Toxicol, 2005, 25, 301-309.

26. Routledge EJ, Parker J, Odum J, Ashby J, Sumpter JP: Some alkyl hydroxyl- benzoate preservatives (parabens) are estrogenic. Toxicol Appl Pharmacol, 1998, 153, $12-19$.

27. Vanparys C, Maras M, Lenjou M, Robbens J, Van Bockstaele D, Blust R, De Coen W: Flow cytometric cell cycle analysis allows for rapid screening of estrogenicity in MCF-7 breast cancer cells. Toxicol In Vitro, 2006, 20, 1238-1248.

28. van Duursen MB, Sanderson JT, van der Bruggen M, van der Linden J, van den Berg M: Effects of several dioxin-like compounds on estrogen metabolism in the malignant MCF-7 and nontumorigenic MCF-10A human mammary epithelial cell lines. Toxicol Appl Pharmacol, 2003, 190, 241-250.

29. van Meeuwen JA, van Son O, Piersma AH, de Jong PC, van den Berg M: Aromatase inhibiting and combined estrogenic effects of parabens and estrogenic effects of other additives in cosmetics. Toxicol Appl Pharmacol, 2008, 230, 372-382.

30. Welshons WV, Thayer KA, Judy BM, Taylor JA, Curran EM, vom Saal FS: Large effects from small exposures. I. Mechanisms for endocrine-disrupting chemicals with estrogenic activity. Environ Health Perspect, 2003, 111, 994-1006.

31. Zientek-Targosz H, Kunnev D, Hawthorn L, Venkov M, Matsui S, Cheney RT, Ionov Y: Transformation of MCF-10A cells by random mutagenesis with frameshift mutagen ICR191: a model for identifying candidate breast-tumor suppressors. Mol Cancer, 2008, 5, 7-51.

Received: January 20, 2012; in the revised form: October 8, 2012; accepted: November 2, 2012. 